\title{
PERBANDINGAN KOMPETENSI MAHASISWA YANG DIBERI RESITASI PETA KONSEP DENGAN MENJAWAB PERTANYAAN SEBELUM MELAKSANAKAN PRAKTIKUM FISIKA DASAR DI LABORATORIUM FISIKA DASAR STKIP PGRI SUMATERA BARAT
}

\author{
Zulpadrianto $^{1}$, Husna ${ }^{2}$ \\ ${ }^{1}$ Staf laboratorium program studi fisika, STKIP PGRI Sumatera Barat \\ ${ }^{2}$ Staf Pengajar Program studi pendidikan fisika, STKIP PGRI Sumatera Barat \\ zpadrianto@gmail.com
}

http://dx.doi.org/10.22202/irfes.2015.v2i1.1789

\begin{abstract}
The lack of sufficient knowledge to students before the beginning of the practicum occurred, causing at least the students who participated in the process lab. These obstacles can be overcome by giving recitation and the provision of appropriate laboratory models. Giving recitation form of a concept map and answer the question that started the lab is expected to improve student learning competencies.

This study was an experimental study with design of The Static Group Comparison Design. Its population is a physical education student STKIP PGRI West Sumatra. instrument is used in this research is the final test for cognitive, observation sheets for the students' learning activities affective, and psychomotor observation sheet. The hypothesis in this study were tested using t-test for normally distributed data and has a homogeneous variance.

The results showed that, on the cognitive differences by student learning outcomes with student concept maps recitation by recitation answered questions. Where the value of the experimental class 1 is 83.37 , while the experimental class 2 value is 79.70 . In the affective domain there are differences in learning outcomes of students who were given a recitation recitation of concept maps to answer questions. Where the value of the experimental class 1 is 79.96 , while the value of the experimental class 274.22 . While on psychomotor there is no difference between the students who were given a recitation recitation of concept maps to answer questions. Where the value of the experiment 163.62 and experimental class 2 value is 60.67 .
\end{abstract}

Keywords : experiment, recitation, concept maps, answer questions, and student competency

\begin{abstract}
ABSTRAK
Kurangnya bekal pengetahuan awal bagi mahasiswa sebelum praktikum berlansung, menyebabkan sedikitnya mahasiswa yang ikut berpartisipasi dalam proses praktikum. Kendala tersebut dapat diatasi dengan pemberian resitasi serta pemberian model praktikum yang tepat. Pemberian resitasi berupa peta konsep serta menjawab pertanyaan yang mengawali praktikum diharapkan dapat meningkatkan kompetensi belajar mahasiswa.

Penelitian ini merupakan penelitian eksperimen dengan rancangan The Static Group Comparison Design. Populasinya adalah mahasiswa pendidikan fisika STKIP PGRI Sumatera Barat. nstrumen penelitian yang digunakan adalah tes akhir untuk ranah kognitif, lembar pengamatan aktivitas belajar mahasiswa untuk ranah afektif, dan lembar observasi untuk ranah psikomotor. Hipotesis pada penelitian ini diuji menggunakan uji-t karena data terdistribusi normal dan memiliki varians yang homogen.

Hasil penelitian menunjukan bahwa, pada ranah kognitif terdapat perbedaan hasil belajar mahasiswa yang diberi resitasi peta konsep dengan mahasiswa yang diberi resitasi menjawab pertanyaan. Dimana nilai kelas eksperimen 1 adalah 83,37, sedangkan nilai kelas eksperimen 2 adalah 79,70. Pada ranah afektif terdapat perbedaan hasil belajar mahasiswa yang diberi resitasi peta konsep dengan resitasi menjawab pertanyaan. Dimana nilai kelas eksperimen 1 adalah 79,96 sedangkan nilai pada kelas eksperimen 274,22 . Sedangkan pada ranah psikomotor tidak terdapat perbedaan antara mahasiswa yang diberi resitasi peta konsep dengan resitasi menjawab pertanyaan. Dimana nilai eksperimen 1 63,62 dan nilai kelas eksperimen 2 adalah 60,67.
\end{abstract}

Kata kunci : eksperiment, resitasi, peta konsep, menjawab pertanyaan, dan kompetensi mahasiswa 


\section{PENDAHULUAN}

Fisika dasar merupakan salah satu mata pelajaran wajib bagi mahasiswa fisika. Mata kuliah fisika tidak hanya dalam bentuk teori tapi juga praktek. Praktek bertujuan untuk mempermudah pemahaman mahasiswa tentang konsep dasar dan applikasi dari apa yang dipelajari secara teori. Materi fisika cenderung disajikan dalam bentuk rumus-rumus yang harus dihafalkan mahasiswa, menimbulkan persepsi kepada mahasiswa bahwa fisika merupakan ilmu yang menekankan pada hafalan rumus, padahal fisika merupakan ilmu yang menekankan pada pemahaman, aplikasi, dan evaluasi.

Ada beberapa faktor yang mempengaruhi ketidak tuntasan belajar mahasiswa. Berdasarkan wawancara penulis dengan Ibu Silvi trisna. M.Pd, terungkap bahwa mahasiswa kurang berpartisipasi aktif dalam praktikum. Hal tersebut dapat terlihat pada saat praktikum berlangsung mahasiswa jarang yang mau bertanya ataupun menjawab pertanyaan. Di samping itu, kemungkinan lain yang menyebabkan rendahnya hasil belajar mahasiswa adalah kegiatan praktikum yang masih belum dapat meningkatkan motivasi mahasiswa untuk belajar secara mandiri. Untuk mengatasi hal tersebut, pembimbing praktikum memberikan resitasi menjawab pertanyaan kepada mahasiswa supaya dapat mengatasi kondisi yang monoton saat proses praktikum berlangsung.

Pada dasarnya pembimbing praktikum sangat berperan dalam meningkatkan motivasi mahasiswa untuk berpartisipasi dalam proses praktikum. Selain itu pembimbing praktikum juga harus mampu menciptakan proses praktikum yang menyenangkan, menantang serta dapat memotivasi kreativitas dan kemandirian mahasiswa. Dengan demikian pembimbing praktikum harus mampu memberikan resitasi yang sesuai dengan karakteristik mahasiswa. Agar resitasi tidak di anggap mahasiswa sebagai beban berat atau merasa terpaksa dalam melakukannya. Maka pembimbing praktikum harus merancang metode praktikum secara efektif dan efisien serta dapat menimbulkan kreativitas mahasiswa. Untuk memberikan ruang yang cukup bagi mahasiswa agar bisa mengembangkan kreativitas serta kemandiriannya, resitasi yang dapat memotivasi mahasiswa untuk berkreativitas adalah peta konsep. Peta konsep dapat memunculkan konsepkonsep yang penting lalu menggambarkan jalinan antar konsep, selain itu dengan peta konsep mahasiswa dapat berkreasi namun tetap membangun pengetahuannya. Penelitian yang dilakukan oleh Zanelia, $(2011)^{[10]}$, menemukan bahwa "Suatu konsep akan lebih mudah diterima siswa apabila digambarkan dalam bentuk peta konsep." Sehingga, resitasi berupa peta konsep baik diberiakan kepada mahasiswa. Menurut Trianto (2007: 157) ${ }^{[9]}$ penggunaan peta konsep dapat membantu pembimbing praktikum dalam mengajar, bahwa peta konsep membantu mahasiswa dalam memahami macam-macam konsep yang ditanamkan di topik lebih besar yang diajarkan.

Agar kedua resitasi tersebut dapat berfungsi optimal, maka perlu diberikan model praktikum yang tepat dalam pengaplikasiannya.Salah satu model praktikum yang tepat digunakan dalam menyempurnakan pemberian resitasi di STKIP PGRI Sumatera Barat adalah dengan menerapkan model praktikum kooperatif tipe discussion. (Suprijono, 
2009: 109$)^{[8]}$ mengungkapkan bahwa "Model Talking Stick mendorong mahasiswa untuk berani mengemukakan pendapat".

Berdasarkan uraian tersebut, penulis melakukan penelitian perbandingan tentang kompetensi belajar fisika yang diberi resitasi peta konsep dengan menjawab pertanyaan sebelum praktikum dilaksanakan di Program Studi Pendidikan Fisika STKIP PGRI Sumatera Barat.

\section{METODE PENELITIAN}

Jenis penelitian adalah penelitian eksperimen.Rancangan penelitian yang digunakan dalam penelitian ini adalah "The Static Group Comparison Design". Dalam penelitian ini, maka dibagi atas kelas eksperimen I dan eksperimen II. Kedua kelas diberikan perlakuan yang berbeda namun dikenai pengukuran yang sama. Kelas eksperimen I diberikan resitasi berupa peta konsep sedangkan kelas eksperimen II diberikan resitasi berupa menjawab pertanyaan yang nantinya kedua kelas tersebut diberikan tes akhir untuk melihat perbedaan kompetensi belajar mahasiswa.

Populasi pada penelitian ini adalah seluruh mahasiswa fisika STKIP PGRI Sumatera Barat tahun masuk 2015 yang terdaftar pada semester ganjil Tahun Pelajaran 2015/2016, dapat dilihat pada Tabel 3. Tabel 1: Jumlah Mahasiswa Mahasiswa fisika tahun masuk 2015 STKIP PGRI Sumatera Barat TP. 2015/2016

\begin{tabular}{|c|c|c|}
\hline Kelas & $\begin{array}{c}\text { Rata- } \\
\text { rata nilai } \\
\text { Kuis }\end{array}$ & $\begin{array}{c}\text { Jumlah } \\
\text { Mahasiswa }\end{array}$ \\
\hline 2015A & 69,28 & 21 \\
\hline
\end{tabular}

\begin{tabular}{|c|c|c|}
\hline Kelas & $\begin{array}{c}\text { Rata- } \\
\text { rata nilai } \\
\text { Kuis }\end{array}$ & $\begin{array}{c}\text { Jumlah } \\
\text { Mahasiswa }\end{array}$ \\
\hline 2015B & 72,61 & 23 \\
\hline
\end{tabular}

Sumber : Laboran fisika STKIP PGRI

Sumatera Barat

Penentuan sampel pada penelitian ini menggunakan teknik purposive sampling, dengan pertimbangan nilai ratarata yang sama serta pembimbing praktikum yang mengajar sama.

Variabel pada penelitian ini terdiri dari 2, yaitu variabel bebas dan variabel terikat. Variabel bebas pada penelitian ini adalah pemberian peta konsep dan menjawab pertanyaan. Variabel terikat adalah kompetensi praktikum Fisika mahasiswa yang diperoleh setelah perlakuan diberikan.

Jenis data yang digunakan pada penelitian ini adalah data primer, yang diambil langsung dari kedua kelas sampel. Untuk memperoleh data dalam penelitian ini, maka perlu dilakukan beberapa tahap berikut ini.

\section{Tahap persiapan}

a. Penentuan jadwal kegiatan penelitian Jadwal penelitian dilaksanakan pada semester ganjil tahun ajaran 2015/2016

b. Mempersiapkan perangkat praktikum untuk kelas eksperimen I dan kelas eksperimen II.

\section{Tahap Pelaksanaan}

Tahap pelaksanaan pada penelitian ini dilakukan sebanyak 8x pertemuan, dimana $7 x$ pertemuan untuk proses praktikum serta $1 x$ pertemuan untuk tes akhir. 
Tabel 2. Tahapan Pelaksanaan Penelitian

\begin{tabular}{|c|c|}
\hline Kelas Ekspe & Kelas Eksp \\
\hline $\begin{array}{l}\text { I. Pendahulua } \\
\text { n }\end{array}$ & $\begin{array}{l}\text { I. Pendahulua } \\
\text { n }\end{array}$ \\
\hline $\begin{array}{l}\text { 1. Pembimbing } \\
\text { praktikum membuka } \\
\text { Praktikum dengan } \\
\text { membaca salam. }\end{array}$ & $\begin{array}{l}\text { 1. Pembimbing } \\
\text { praktikum membuka } \\
\text { pelajaran dengan } \\
\text { membaca salam. }\end{array}$ \\
\hline $\begin{array}{l}\text { 2. Pembimbing } \\
\text { praktikum meminta } \\
\text { salah satu peserta } \\
\text { didik untuk } \\
\text { memimpin doa. }\end{array}$ & $\begin{array}{l}\text { 2. Pembimbing } \\
\text { praktikum meminta } \\
\text { salah satu peserta } \\
\text { didik untuk } \\
\text { memimpin doa. }\end{array}$ \\
\hline $\begin{array}{l}\text { 3. Pembimbing } \\
\text { praktikum } \\
\text { mengecek kehadiran } \\
\text { mahasiswa. }\end{array}$ & $\begin{array}{l}\text { 3. Pembimbing } \\
\text { praktikum } \\
\text { mengecek kehadiran } \\
\text { peserta didik. }\end{array}$ \\
\hline $\begin{array}{l}\text { 4. Pembimbing } \\
\text { praktikum } \\
\text { memeriksa kesiapan } \\
\text { kelas. }\end{array}$ & $\begin{array}{l}\text { 4. Pembimbing } \\
\text { praktikum } \\
\text { memeriksa kesiapan } \\
\text { kelas. }\end{array}$ \\
\hline $\begin{array}{l}\text { 5. Pembimbing } \\
\text { praktikum } \\
\text { memberikan } \\
\text { apersepsi }\end{array}$ & $\begin{array}{l}\text { 5. Pembimbing } \\
\text { praktikum } \\
\text { memberikan } \\
\text { apersepsi }\end{array}$ \\
\hline $\begin{array}{l}\text { 6. Pembimbing } \\
\text { praktikum } \\
\text { memberikan } \\
\text { motivasi. }\end{array}$ & $\begin{array}{l}\quad 6 . \quad \text { Pembimbing } \\
\text { praktikum } \\
\text { memberikan } \\
\text { motivasi. }\end{array}$ \\
\hline \begin{tabular}{l}
\multicolumn{1}{c}{ 7. Pembimbing } \\
praktikum \\
menyampaikan \\
tujuan praktikum \\
dan model \\
praktikum yang \\
akan digunakan \\
pada praktikum \\
pada materi saat itu.
\end{tabular} & \begin{tabular}{l}
\multicolumn{1}{c}{ 7. Pembimbing } \\
praktikum \\
menyampaikan \\
tujuan praktikum \\
dan model \\
praktikum yang \\
akan digunakan \\
pada praktikum \\
pada materi saat itu.
\end{tabular} \\
\hline
\end{tabular}

\begin{tabular}{|c|c|}
\hline $\begin{array}{l}\text { 8. Pembimbing } \\
\text { praktikum } \\
\text { menyampaikan } \\
\text { cakupan materi dan } \\
\text { menjelasan uraian } \\
\text { kegiatan sesuai } \\
\text { silabus. }\end{array}$ & $\begin{array}{l}\quad 8 . \quad \text { Pembimbing } \\
\text { praktikum } \\
\text { menyampaikan } \\
\text { cakupan materi dan } \\
\text { menjelasan uraian } \\
\text { kegiatan sesuai } \\
\text { silabus. }\end{array}$ \\
\hline $\begin{array}{l}\text { 9. Pembimbing } \\
\text { praktikum } \\
\text { menyuruh } \\
\text { mahasiswa } \\
\text { mengumpulkan } \\
\text { tugas peta konsep. }\end{array}$ & $\begin{array}{l}\text { 9. Pembimbing } \\
\text { praktikum } \\
\text { menyuruh } \\
\text { mahasiswa } \\
\text { mengumpulkan } \\
\text { tugas menjawab } \\
\text { pertanyaan. }\end{array}$ \\
\hline
\end{tabular}

\begin{tabular}{|c|c|}
\hline Melaksanakan & Melaksanakan \\
\hline $\begin{array}{l}\text { praktikum dengan } \\
\text { model yang telah } \\
\text { diberi resitasi peta } \\
\text { konsep. }\end{array}$ & $\begin{array}{l}\text { praktikum dengan } \\
\text { menjawab } \\
\text { pertanyaan }\end{array}$ \\
\hline 1. Pembimbing & 1. Pembimbing \\
\hline praktikum membagi & praktikum membagi \\
\hline mahasiswa menjadi & mahasiswa menjadi \\
\hline 5 kelompok yang & 5 kelompok yang \\
\hline terdiri dari 5 orang & terdiri dari 5 orang \\
\hline mahasiswa yang & mahasiswa yang \\
\hline dikelompokan & dikelompokan \\
\hline secara heterogen & secara heterogen \\
\hline (pembagian & (pembagian \\
\hline kelompok dilakukan & kelompok dilakukan \\
\hline pada pertemuan & pada pertemuan \\
\hline sebelumnya untuk & sebelumnya untuk \\
\hline menghemat waktu). & menghemat waktu). \\
\hline 2. Pembimbing & 2. Pembimbing \\
\hline praktikum & praktikum \\
\hline mengoreksi salah & mengoreksi salah \\
\hline satu resitasi peta & satu resitasi \\
\hline konsep yang telah & menjawab \\
\hline dibuat oleh & pertanyaan yang \\
\hline mahasiswa dan & telah dibuat oleh \\
\hline mendiskusi-kan & mahasiswa dan \\
\hline bersama mahasiswa & mendiskusi-kan \\
\hline tentang konsep- & bersama mahasiswa \\
\hline
\end{tabular}




\begin{tabular}{|c|c|}
\hline $\begin{array}{l}\text { konsep yang telah } \\
\text { dipahami oleh } \\
\text { mahasiswa } \\
\text { sebelumnya. }\end{array}$ & $\begin{array}{l}\text { tentang jawaban } \\
\text { yang telah dipahami } \\
\text { oleh mahasiswa } \\
\text { sebelumnya. }\end{array}$ \\
\hline $\begin{array}{l}\text { 3. Pembimbing } \\
\text { praktikum } \\
\text { memberikan } \\
\text { pertanyaan kepada } \\
\text { mahasiswa. }\end{array}$ & $\begin{array}{l}\text { 3. Pembimbing } \\
\text { praktikum } \\
\text { memberikan } \\
\text { pertanyaan kepada } \\
\text { mahasiswa. }\end{array}$ \\
\hline $\begin{array}{l}\text { 4. Praktikum } \\
\text { Dimulai. }\end{array}$ & $\begin{array}{l}\quad \text { 4. Pembimbing } \\
\text { praktikum } \\
\text { mengamati serta } \\
\text { membimbing } \\
\text { jalannya praktikum }\end{array}$ \\
\hline $\begin{array}{l}\text { 5. Mahasiswa } \\
\text { dan pembimbing } \\
\text { praktikum } \\
\text { mendiskusikan } \\
\text { tentang materi } \\
\text { praktikum yang } \\
\text { dipelajari }\end{array}$ & $\begin{array}{l}\quad \text { 5. Setelah } \\
\text { pertanyaan } \\
\text { terjawab, } \\
\text { pembimbing } \\
\text { praktikum terus } \\
\text { memantau dan } \\
\text { berjalan kesetiap } \\
\text { kelompok yang } \\
\text { melakukan } \\
\text { praktikum }\end{array}$ \\
\hline \begin{tabular}{l}
\multicolumn{1}{c}{6 . Pembimbing } \\
praktikum \\
memantau, \\
mengkoordinir dan \\
menyempurnakan \\
jawaban mahasiswa \\
atau menjawab \\
pertanyaan yang \\
tidak bisa dijawab \\
oleh mahasiswa, \\
ketika praktikum.
\end{tabular} & $\begin{array}{l}\text { 6. Mahasiswa } \\
\text { dan pembimbing } \\
\text { praktikum } \\
\text { mendiskusikan } \\
\text { tentang materi yang } \\
\text { dipelajari. }\end{array}$ \\
\hline
\end{tabular}

Tahap akhir

\begin{tabular}{|c|c|}
\hline $\begin{array}{l}\quad 1 . \text { Mahasisw } \\
\text { a bersama } \\
\text { pembimbing } \\
\text { praktikum } \\
\text { menyimpulkan hasil } \\
\text { praktikum }\end{array}$ & $\begin{array}{l}\text { 1. Mahasiswa } \\
\text { bersama } \\
\text { pembimbing } \\
\text { praktikum } \\
\text { menyimpulkan hasil } \\
\text { praktikum }\end{array}$ \\
\hline $\begin{array}{l}\text { 2. Pembimbi } \\
\text { ng praktikum } \\
\text { memberikan tugas } \\
\text { berupa peta konsep } \\
\text { tentang materi } \\
\text { praktikum } \\
\text { selanjutnya. }\end{array}$ & $\begin{array}{l}\text { 2. Pembimbing } \\
\text { praktikum } \\
\text { memberikan resitasi } \\
\text { atau tugas berupa } \\
\text { pertanyaan tentang } \\
\text { materi selanjutnya. }\end{array}$ \\
\hline $\begin{array}{l}\text { 3. Pembimbi } \\
\text { ng praktikum } \\
\text { mengakhiri } \\
\text { praktikum dengan } \\
\text { mengucapkan } \\
\text { hamdalah dan salam }\end{array}$ & $\begin{array}{l}\text { 3. Pembimbing } \\
\text { praktikum } \\
\text { mengakhiri } \\
\text { praktikum dengan } \\
\text { mengucapkan } \\
\text { hamdalah dan } \\
\text { salam. }\end{array}$ \\
\hline
\end{tabular}

3. Tahap pengumpulan dan pengolahan data

Di akhir penelitian, kedua kelas sampel diberikan tes akhir untuk mengukur kompetensi dari mahasiswa. Data dari kompetensi mahasiswa lalu diolah dan dapat ditarik kesimpulannya. Sebelum instrumen digunakan, instrumen tersebut diujicobakan pada kelas lain selain kelas sampel, hal ini bertujuan untuk mendapatkan soal yang baik. Uji coba soal dilakukan pada kelas Biologi 2015A yang juga mengambil mata pelajaran fisika dasar pada tahun ajaran 2015/2016 yang dilakukan oleh 30 orang mahasiswa. Hasil uji coba soal dilakukan uji statistik untuk mendapatkan reliabilitas tes serta daya beda dan indeks kesukaran soal.

a. Menentukan validitas tes

Suatu soal dikatakan valid apabila soal itu dapat mengukur kemampuan mahasiswa yang sebenarnya. Pada penelitian ini, validitas yang diukur adalah 
validitas isi dan validitas item. Validitas isi untuk penelitian ini divalidasi staf pengajar Program Studi Pendidikan Fisika, Ibu Iing rika yanti, M.Pd.

b. Menentukan reliabilitas tes

$$
\text { Untuk menentukan }
$$

reliabilitas tes digunakan rumus KR-21 yang dikemukakan oleh Slameto (2003: 216) ${ }^{[6]}$ berikut ini.

$$
r_{11}=\left(\frac{n}{n-1}\right)\left(1-\frac{M(n-M)}{n S^{2}}\right)
$$

dimana

$$
M=\frac{\sum X}{N} \operatorname{dan} S^{2}=\frac{N \sum X^{2}-(\Sigma X)^{2}}{N(N-1)}
$$

Keterangan :

$$
\begin{aligned}
r_{11}= & \text { reliabilitas tes } \\
& \text { secara keseluruhan } \\
N= & \text { jumlah butir soal tes } \\
\mathrm{M}= & \text { rata-rata skor tes } \\
\mathrm{N}= & \text { jumlah pengikut tes } \\
S^{2}= & \text { varians total } \\
\mathrm{X}= & \text { skor pengikut tes }
\end{aligned}
$$

soal yang digunakan oleh peneliti adalah soal yang memiliki nilai reliabilitas 0,41-1,00 dengan klasifikasi reliabilitas sedang-sangat tinggi.

c. Analisis butir soal

1. Menghitung daya pembeda (D)

Daya pembeda soal (D) dapat dinyatakan dalam rumus sebagai berikut ini.

$$
D=\frac{B_{A}}{J_{A}}-\frac{B_{B}}{J_{B}}=P_{A}-P_{B}
$$

Keterangan :

$\mathrm{J}=$ jumlah peserta tes

$\mathrm{J}_{\mathrm{A}}=$ banyaknya peserta

kelompok atas

$\mathrm{J}_{\mathrm{B}}=$ banyaknya peserta kelompok bawah

$\mathrm{B}_{\mathrm{A}}=$ banyaknya peserta kelompok atas yang menjawab soal itu benar

$\mathrm{B}_{\mathrm{B}}=$ banyaknya peserta kelompok bawah yang menjawab soal itu dengan benar, Arikunto (2008: 213$214)^{[1]}$.

Kriteria soal yang digunakan adalah dengan tingkat daya pembeda $\geq$ 0,21, dengan kriteria cukup-baik sekali.

2. Menentukan tingkat kesukaran soal (P)

Mengetahui indeks kesukaran soal digunakan rumus yang dinyatakan oleh Arikunto (2008: 208) ${ }^{[1]}$ berikut ini.

$$
\mathrm{P}=\frac{B}{J S}
$$

Keterangan :

$$
\begin{aligned}
& \mathrm{P}=\text { Indeks kesukaran soal } \\
& \mathrm{B} \text { = banyaknya mahasiswa yang } \\
& \text { menjawab soal itu dengan betul } \\
& \mathrm{JB}=\text { jumlah seluruh mahasiswa } \\
& \text { peserta tes }
\end{aligned}
$$

Kriteria indeks soal yang digunakan adalah dengan indeks kesukaran $\geq 0,31$ 0,70, dengan kriteria sedang.

d. Analisis data.

Analisis data hasil penelitian ini menggunakan metode statistik untuk melihat pencapaian keberhasilan belajar mahasiswa. Data dianalisis menggunakan uji perbedaan dua rata-rata dengan memakai uji normalitas dan homogenitas data yang diperoleh.

1. Ranah kognitif

\section{a. Uji normalitas}

Uji normalitas bertujuan untuk melihat apakah data berdistribusi normal atau tidak. Uji normalitas memakai uji Lilliefors Sudjana (2005: 466-467) ${ }^{[7]}$ dengan langkah-langkah beriku ini.

1) menyusun data $X_{1}, X_{2}, X_{3}, \ldots, X_{n}$ hasil belajar mahasiswa dalam Tabel mulai dari data yang terkecil hingga data yang terbesar.

2) data $X_{1}, X_{2}, X_{3}, \ldots, X_{n}$ dijadikan bilangan baku $\mathrm{Z}_{1}, \mathrm{Z}_{2}, \mathrm{Z}_{3}, \ldots, \mathrm{Z}_{\mathrm{n}}$ 
dengan rumus : $Z_{1}=\frac{X_{1}-\bar{X}}{S}$

dengan $\mathrm{x}$ dan $\mathrm{S}$ masing-masing adalah rata-rata dan simpangan baku sampel

3) dengan menggunakan daftar terdistribusi normal baku, kemudian dihitungpeluang $\mathrm{F}(\mathrm{Zi})=\mathrm{P}(\mathrm{Z}$ Zzi $)$

4) menentukan harga Szi. yaitu proporsi baku yang lebih kecil atau sama dengan $\mathrm{Zi}$, dengan rumus : $\quad \mathrm{S}\left(\mathrm{Z}_{\mathrm{i}}\right)$ $=\frac{F(Z i)}{n}$

5) hitung selisih $\mathrm{F}(\mathrm{Zi})-\mathrm{S}(\mathrm{Zi})$, kemudian hitung harga mutlaknya

6) diambil harga yang paling besar diantara harga mutlak selisih tersebut yang disebut $\mathrm{L} 0$

7) membanding kan nilai L0 dengan nilai kritis LTabel yang diambil dari taraf nyata yang dipilih. Bila $\mathrm{L}_{0}$ labih kecil dari $\mathrm{L}_{\text {Tabel }}$ maka data berdistribusi normal

b. Uji Homogenitas

Uji homogenitas digunakan untuk melihat apakah data memiliki varians yang homogen atau tidak. Oleh sebab itu, menguji homogenitas data dilakukan uji $\mathrm{F}$, dengan langkah-langkah seperti dikemukakan oleh Sudjana (2005: 249) ${ }^{[7]}$, berikut ini.

1) mencari varians masing-masing kelompok data,kemudian menghitung harga $F$ dengan rumus:

$$
\mathrm{F}=\frac{S_{1}^{2}}{S_{2}^{2}}
$$

keterangan :

F : varians kelompok data

$S_{1}{ }^{2} \quad$ : varians hasil belajar kelas eksperimen I

$\mathrm{S}_{2}{ }^{2}$ : varians hasil belajar kelas eksperimen II

2) dibandingkan harga $F$ tersebut dengan harga $\mathrm{F}$ yang terdapat pada daftar distribusi $F$ dengan taraf signifikan dengan $\mathrm{dk}$ pembilang $=\mathrm{n} 1-1, \mathrm{dk}$ penyebut $=\mathrm{n}_{2}-1$. Bila harga $\mathrm{F}$ hitung itu lebih kecil dari $\mathrm{F}$ Tabel berarti data mempunyai varians yang homogen.

2. Uji Hipotesis

Berdasarkan uji normalitas dan uji homogenitas, maka data yang didapatkan adalah data yang terdistribusi normal dan kedua kelon poilit data homogen, maka digunakan uji t dengan rumus berikut ini.

$$
\begin{aligned}
& t=\frac{\overline{X_{1}}-\overline{X_{2}}}{S \sqrt{\frac{1}{n_{1}}+\frac{1}{n_{2}}}} \text { dengan } S^{2}= \\
& \frac{\left(n_{1}+1\right) S_{1}^{2}+\left(n_{2}-1\right) S_{2}^{2}}{n_{1}+n_{2}-2} \\
& \text { Kenangan: } \\
& 1 \quad: \text { nilai rata-rata kelas } \\
& -\quad \text { : nilai rata-rata kelas } \\
& \text { exsperimen II } \\
& \mathrm{S}_{1}: \text { standar deviasi kelas } \\
& \text { eksperimen I } \\
& \mathrm{S}_{2}: \text { standar deviasi kelas } \\
& \text { eksperimen II } \\
& \mathrm{S}: \text { standar deviasi gabungan } \\
& \mathrm{n}_{1}: \text { jumlah mahasiswa kelas } \\
& \text { eksperimen I } \\
& \mathrm{n}_{2}: \text { jumlah mahasiswa kelas } \\
& \text { eksperimen II }
\end{aligned}
$$

Kriteria pengujian adalah hipotesis diterima jika thitung $>$ tTabel dengan 0,05 dan derajat kebebasan $(\mathrm{dk})=\left(\mathrm{n}_{1}+\mathrm{n}_{2}-2\right)$ (Sudjana, 2005: 239) ${ }^{[8]}$.

2. Ranah afektif

Menganalisis data hasil observasi ranah afektif dilakukan langkah-langkah berikut ini.

a. Pemberian dan penghitungan skor keseluruhan dari tiap indikator yang tampak dalam proses praktikum. Masing-masing aspek terdiri dari tiga indikator penilaian. Jika pada setiap 
aspek terlihat indikator tersebut, maka diberi tanda ceklis $(\sqrt{ })$ pada kolom yang disediakan dalam format penilaian ranah afektif. Setelah mendapatkan data penilaian keseluruhan maka skor yang diperoleh dari setiap indikator dijumlahkan.

b. Skor total yang diperoleh dikonversikan menjadi nilai dengan rumus yang terdapat dalam Purwanto (2012: 102) ${ }^{[4]}$ berikut ini.

$$
N P=\frac{R}{S M} \times 100 \%
$$

Keterangan :

$$
\begin{aligned}
& \mathrm{NP}=\text { Nilai afektif mahasiswa } \\
& \mathrm{R}=\text { Skor total mahasiswa } \\
& \mathrm{SM}=\text { Skor maksimum }
\end{aligned}
$$

1) Uji normalitas

Uji normalitas bertujuan untuk melihat apakah data berdistribusi normal atau tidak. Uji normalitas memakai uji Lilliefors Sudjana (2005: 466-467) ${ }^{[7]}$ dengan langkah-langkah berikut ini.

a) menyusun data $X_{1}, X_{2}, X_{3}, \ldots, X_{n}$ hasil belajar mahasiswa dalam Tabel mulai dari data yang terkecil hingga data yang terbesar

b) data $\mathrm{X}_{1}, \mathrm{X}_{2}, \mathrm{X}_{3}, \ldots, \mathrm{X}_{\mathrm{n}} \quad$ dijadikan bilangan baku $\mathrm{Z}_{1}, \mathrm{Z}_{2}, \mathrm{Z}_{3}, \ldots, \mathrm{Z}_{\mathrm{n}}$

$$
\text { dengan rumus }: Z_{1}=\frac{X_{1}-\bar{X}}{S}
$$

dengan $\mathrm{x}$ dan $\mathrm{S}$ masing-masing adalah rata-rata dan simpangan baku sampel

c) dengan menggunakan daftar terdistribusi normal baku, kemudian dihitung peluang $\mathrm{F}(\mathrm{Zi})=\mathrm{P}(\mathrm{Z}$ \Zi $)$

d) menentukan harga Szi. yaitu proporsi baku yang lebih kecil atau sama dengan $\mathrm{Zi}$, dengan rumus : $\mathrm{S}\left(\mathrm{Z}_{\mathrm{i}}\right)=$ $\frac{F(Z i)}{n}$

e) hitung selisih $\mathrm{F}(\mathrm{Zi})-\mathrm{S}(\mathrm{Zi})$, kemudian hitung harga mutlaknya f) diambil harga yang paling besar diantara harga mutlak selisih tersebut yang disebut $\mathrm{L} 0$

g) membandingkan nilai L0 dengan nilai kritis LTabel untuk taraf nyata yang dipilih. Bila $\mathrm{L}_{0}$ labih kecil dari $\mathrm{L}_{\text {Tabel }}$ maka data berdistribusi normal.

1) Uji Homogenitas

Uji homogenitas digunakan untuk melihat apakah data memiliki varians yang homogen atau tidak. Oleh sebab itu, menguji homogenitas data dilakukan uji $\mathrm{F}$, dengan langkahlangkah seperti dikemukakan oleh Sudjana (2005: 249) ${ }^{[7]}$, berikut ini.

a) mencari varians masing-masing kelompok data, kemudian menghitung harga $\mathrm{F}$ dengan rumus:

$$
\mathrm{F}=\frac{S_{1}^{2}}{S_{2}^{2}}
$$

keterangan :

F : varians kelompok data

$S_{1}^{2} \quad$ : varians hasil belajar kelas eksperimen I

$\mathrm{S}_{2}{ }^{2}$ : varians hasil belajar kelas eksperimen II

b) dibandingkan harga $F$ tersebut, $F_{\text {hitung }}$ dengan $F_{\text {Tabel, }}$, harga $F$ yang terdapat pada daftar distribusi $\mathrm{F}$ dengan taraf signifikan dengan $\mathrm{dk}$ pembilang $=\mathrm{n} 1-$ 1 , dk penyebut $=\mathrm{n}_{2}-1$. Bila harga $\mathrm{F}_{\text {hitung }}$ itu lebih kecil dari $\mathrm{F}_{\text {Tabel }}$ berarti data mempunyai varians yang homogen.

2) Uji Hipotesis

Berdasarkan uji normalitas dan uji homogenitas, maka data yang didapatkan adalah data yang terdistribusi normal dan kedua kelompok data homogen, maka untuk uji hipotesis digunakan uji t dengan rumus berikut ini. 
$t=\frac{\overline{X_{1}}-\overline{X_{2}}}{S \sqrt{\frac{1}{n_{1}}+\frac{1}{n_{2}}}} \quad$ dengan $\quad S^{2}=$

$\frac{\left(n_{1}-1\right) S_{1}^{2}+\left(n_{2}-1\right) S_{2}^{2}}{n_{1}+n_{2}-2}$

beterangan :

$\left[\bar{i}_{1}\right.$ : nilai rata-rata kelas eksperimen I

$\left\lceil\bar{H}_{2}\right.$ : nilai rata-rata kelas eksperimen II

s. : standar deviasi kelas eksperimen I

$\mathrm{S}_{2}$ : standar deviasi kelas eksperimen II

$\mathrm{S}$ : standar deviasi gabungan

$\mathrm{n}_{1}$ : jumlah mahasiswa kelas eksperimen I

$\mathrm{n}_{2}$ : jumlah mahasiswa kelas eksperimen II

Kriteria pengujian adalah hipotesis diterima jika thitung $>$ tTabel dengan 0,05 dan derajat kebebasan $(\mathrm{dk})=(\mathrm{n} 1+\mathrm{n} 2-2)$ (Sudjana, 2005: 239) ${ }^{[7]}$.

\section{Ranah Psikomotor}

Dalam menganalisis data hasil observasi dilakukan langkah-langkah sebagai berikut ini.

a. Menjumlahkan skor total yang diperoleh mahasiswa.

b. Mengkonversikan skor total yang diperoleh menjadi nilai dengan rumus yang terdapat dalam Purwanto (2012: $112)^{[5]}$ berikut ini.

$$
S=\frac{R}{N} \times 100
$$

Keterangan :

$\mathrm{S}=$ nilai yang diharapkan

$\mathrm{R}=$ jumlah skor dari item atau soal yang dijawab benar

$\mathrm{N}=$ skor maksimum dari tes tersebut

1) Uji normalitas

Uji normalitas bertujuan untuk melihat apakah data berdistribusi normal atau tidak. Uji normalitas memakai uji Lilliefors Sudjana (2005: 466-467) ${ }^{[7]}$ dengan langkah-langkah berikut ini. a) menyusun data $X_{1}, X_{2}, X_{3}, \ldots, X_{n}$ hasil belajar mahasiswa dalam Tabel mulai dari data yang terkecil hingga data yang terbesar

b) data $\mathrm{X}_{1}, \mathrm{X}_{2}, \mathrm{X}_{3}, \ldots, \mathrm{X}_{\mathrm{n}}$ dijadikan bilangan baku $\mathrm{Z}_{1}, \mathrm{Z}_{2}, \mathrm{Z}_{3}, \ldots, \mathrm{Z}_{\mathrm{n}}$ dengan rumus : $Z_{1}=\frac{X_{1}-\bar{X}}{S}$ dengan $\mathrm{x}$ dan $\mathrm{S}$ masing-masing adalah rata-rata dan simpangan baku sampel

c) dengan menggunakan daftar terdistribusi normal baku, kemudian dihitung peluang $\mathrm{F}(\mathrm{Zi})=\mathrm{P}(\mathrm{Z}$ \Zi $)$

d) menentukan harga Szi. yaitu proporsi baku yang lebih kecil atau sama dengan $\mathrm{Zi}$, dengan rumus : $\mathrm{S}\left(\mathrm{Z}_{\mathrm{i}}\right)=$ $\frac{F(Z i)}{n}$

e) hitung selisih $\mathrm{F}(\mathrm{Zi})-\mathrm{S}(\mathrm{Zi})$, kemudian hitung harga mutlaknya

f) diambil harga yang paling besar diantara harga mutlak selisih tersebut yang disebut $\mathrm{LO}$

g) membanding kan nilai L0 dengan nilai kritis LTabel yang diambil dari taraf nyata yang dipilih. Bila $\mathrm{L}_{0}$ labih kecil dari $\mathrm{L}_{\text {Tabel }}$ maka data berdistribusi normal

a. Uji Homogenitas

Uji homogenitas digunakan untuk melihat apakah data memiliki varians yang homogen atau tidak.

Oleh sebab itu, menguji homogenitas data dilakukan uji $\mathrm{F}$, dengan langkahlangkah seperti dikemukakan oleh Sudjana (2005: 249) ${ }^{[8]}$, berikut ini.

a) mencari varians masing-masing kelompok data, kemudian menghitung harga $\mathrm{F}$ dengan rumus:

$$
\mathrm{F}=\frac{S_{1}^{2}}{S_{2}^{2}}
$$

keterangan :

F : varians kelompok data 
$S_{1}^{2}$ : varians hasil belajar kelas eksperimen I

$\mathrm{S}_{2}^{2}$ : varians hasil belajar kelas eksperimen II

b) dibandingkan harga $F$ tersebut dengan harga $F$ yang terdapat pada daftar distribusi $\mathrm{F}$ dengan taraf signifikan dengan $\mathrm{dk}$ pembilang $=\mathrm{n} 1-1, \mathrm{dk}$ penyebut $=\mathrm{n} 2-1$. Bila harga $\mathrm{F}$ hitung itu lebih kecil dari F Tabel berarti data mempunyai varians yang homogen.

b. Uji Hipotesis

Berdasarkan uji normalitas dan uji homogenitas, maka data yang didapatkan adalah data yang terdistribusi normal dan kedua kelompok data homogen, maka digunakan uji t dengan rumus berikut ini.

$$
\begin{array}{r}
t=\frac{\overline{X_{1}}-\overline{X_{2}}}{S \sqrt{\frac{1}{n_{1}}+\frac{1}{n_{2}}}} \text { dengan } \\
S^{2}=-\frac{\left(n_{1}-1\right) S_{1}^{2}+\left(n_{2}-1\right) S_{2}^{2}}{n_{1}+n_{2}-2}
\end{array}
$$

Keteangan :

$$
\left[i_{1}\right. \text { : nilai rata-rata kelas }
$$

eksperimen I

$\left[i_{2}\right.$ : nilai rata-rata kelas

eksporimen II

$\mathrm{S}_{1}$ : standar deviasi kelas eksperimen I

$\mathrm{S}_{2}$ : standar deviasi kelas eksperimen II

$\mathrm{S}$ : standar deviasi gabungan

$\mathrm{n}_{1}$ : jumlah mahasiswa kelas eksperimen I

$\mathrm{n}_{2}$ : jumlah mahasiswa kelas eksperimen II

Kriteria pengujian adalah hipotesis diterima jika thitung > tTabel dengan 0,05 dan derajat kebebasan $(\mathrm{dk})=(\mathrm{n} 1+\mathrm{n} 2-2)$

(Sudjana, 2005: 239) ${ }^{[7]}$.

\section{HASIL DAN PEMBAHASAN}

Data hasil penelitian tentang perbandingan kompetensi belajar mahasiswa yang diberikan resitasi berupa peta konsep dengan resitasi menjawab pertanyaan sebelum praktikum mahasiswa fisika tahun

\begin{tabular}{|c|c|c|c|}
\hline \multirow[b]{2}{*}{$\begin{array}{c}\text { Paramete } \\
\text { r }\end{array}$} & \multicolumn{2}{|c|}{ Kelass } & \multirow[b]{2}{*}{$\begin{array}{c}\text { Keteran } \\
\text { gan }\end{array}$} \\
\hline & $\begin{array}{c}\text { Ekspeeri } \\
\text { men } \\
\text { I }\end{array}$ & $\begin{array}{c}\text { Eksperim } \\
\text { en } \\
\text { II }\end{array}$ & \\
\hline \multicolumn{4}{|c|}{ Kognitif } \\
\hline Rata-rata & 83,37 & 79,70 & $\begin{array}{l}\bar{X}_{1}> \\
\bar{X}_{2}\end{array}$ \\
\hline $\begin{array}{c}\text { Uji } \\
\text { Nornalitas }\end{array}$ & $\begin{array}{l}\mathrm{L}_{\mathrm{o}=} \\
0,1371 \\
\mathrm{~L}_{\mathrm{t}=} 0,148\end{array}$ & $\begin{array}{l}\mathrm{L}_{\mathrm{o}}=0,126 \\
1 \\
\mathrm{~L}_{\mathrm{t}}=0,161\end{array}$ & $\begin{array}{c}\text { Terdistr } \\
\text { ibu-si } \\
\text { Normal }\end{array}$ \\
\hline $\begin{array}{c}\text { Uji } \\
\text { Homogenit } \\
\text { as }\end{array}$ & \multicolumn{2}{|c|}{$\begin{array}{c}\mathrm{F}_{\text {hitung }}=0,65 \\
\mathrm{~F}_{\text {tabel }}=1,74\end{array}$} & $\begin{array}{c}\mathrm{F}_{\text {hitung }}< \\
\mathrm{F}_{\text {Tabel }} \\
\text { Varians } \\
\text { Homog } \\
\text { en. }\end{array}$ \\
\hline $\begin{array}{c}\text { Uji } \\
\text { Hipotesis }\end{array}$ & \multicolumn{2}{|c|}{$\begin{array}{c}\mathrm{t}_{\text {hitung }}=2,01 \\
\mathrm{t}_{\text {tabel }}=1,67\end{array}$} & $\begin{array}{c}\mathrm{t}_{\text {hitung }}>\mathrm{t} \\
\text { Tabel } \\
\text { Hipotes } \\
\text { is } \\
\text { Diterim } \\
\text { a }\end{array}$ \\
\hline \multicolumn{4}{|c|}{ Afektif } \\
\hline Rata-rata & 69.69 & 62.89 & $\begin{array}{l}\bar{X}_{1}> \\
\bar{X}_{2}\end{array}$ \\
\hline $\begin{array}{c}\text { Uji } \\
\text { Nornalitas }\end{array}$ & $\begin{array}{c}\mathrm{L}_{\mathrm{o}}=0,126 \\
3 \\
\mathrm{~L}_{\mathrm{t}}=0,148\end{array}$ & $\begin{array}{c}\mathrm{L}_{\mathrm{o}}=0,118 \\
4 \\
\mathrm{~L}_{\mathrm{t}}=0,161\end{array}$ & $\begin{array}{c}\text { Terdistr } \\
\text { ibu-si } \\
\text { Normal }\end{array}$ \\
\hline $\begin{array}{c}\text { Uji } \\
\text { Homogenit } \\
\text { as }\end{array}$ & \multicolumn{2}{|c|}{$\begin{array}{c}\mathrm{F}_{\text {hitung }}=0.42 \\
\mathrm{~F}_{\text {tabel }}=1,74\end{array}$} & $\begin{array}{c}\mathrm{F}_{\text {hitung }}< \\
\mathrm{F}_{\text {Tabel }} \\
\text { Varians }\end{array}$ \\
\hline
\end{tabular}
masuk 2015 STKIP PGRI Sumatera Barat, dipaparkan pada Tabel 3 berikut ini 


\begin{tabular}{|c|c|c|c|}
\hline & & & $\begin{array}{c}\text { Homog } \\
\text { en. }\end{array}$ \\
\hline $\begin{array}{c}\text { Uji } \\
\text { Hipotesis }\end{array}$ & \multicolumn{2}{|c|}{$\begin{array}{c}\mathrm{t}_{\text {hitung }}=2.51 \\
\mathrm{t}_{\text {tabel }}=1,67\end{array}$} & $\begin{array}{c}\mathrm{t}_{\text {hitung }}>\mathrm{t} \\
\text { Tabel } \\
\text { Hipotes } \\
\text { is } \\
\text { Diterim } \\
\text { a }\end{array}$ \\
\hline \multicolumn{4}{|c|}{ Psikomotor } \\
\hline Rata-rata & 63.62 & 60.67 & $\begin{array}{l}\bar{X}_{1>}> \\
\bar{X}_{2}\end{array}$ \\
\hline $\begin{array}{c}\text { Uji } \\
\text { Nornalitas }\end{array}$ & $\begin{array}{l}\mathrm{L}_{\mathrm{o}}=0,140 \\
\mathrm{~L}_{\mathrm{t}}=0,148\end{array}$ & $\begin{array}{l}\mathrm{L}_{\mathrm{o}}=0,138 \\
\mathrm{~L}_{\mathrm{t}}=0,161\end{array}$ & $\begin{array}{l}\text { Terdistr } \\
\text { ibu-si } \\
\text { Normal }\end{array}$ \\
\hline $\begin{array}{c}\text { Uji } \\
\text { Homogenit } \\
\text { as }\end{array}$ & \multicolumn{2}{|c|}{$\begin{array}{c}F_{\text {hitung }}=0,59 \\
F_{\text {tabel }}=1,74\end{array}$} & $\begin{array}{c}\mathrm{F}_{\text {hitung }}< \\
\mathrm{F}_{\text {Tabel }} \\
\text { Varians } \\
\text { Homog } \\
\text { en. }\end{array}$ \\
\hline $\begin{array}{c}\text { Uji } \\
\text { Hipotesis }\end{array}$ & \multicolumn{2}{|c|}{$\begin{array}{c}\mathrm{t}_{\text {hitung }}=0,82 \\
\mathrm{t}_{\text {tabel }}=1,67\end{array}$} & $\begin{array}{c}\mathrm{t}_{\text {hitung }}<\mathrm{t} \\
\text { Tabel, } \\
\text { Hipotes } \\
\text { is } \\
\text { Ditolak }\end{array}$ \\
\hline
\end{tabular}

Berdasarkan hasil pada Tabel 3. ,terlihat bahwa Hasil penelitian menunjukan bahwa, pada ranah kognitif terdapat perbedaan hasil belajar mahasiswa yang diberi resitasi peta konsep dengan mahasiswa yang diberi resitasi menjawab pertanyaan. Dimana nilai kelas eksperimen 1 adalah 83,37, sedangkan nilai kelas eksperimen 2 adalah 79,70. Pada ranah afektif terdapat perbedaan hasil belajar mahasiswa yang diberi resitasi peta konsep dengan resitasi menjawab pertanyaan. Dimana nilai kelas eksperimen 1 adalah 79,96 sedangkan nilai pada kelas eksperimen 2 74,22. Sedangkan pada ranah psikomotor tidak terdapat perbedaan antara mahasiswa yang diberi resitasi peta konsep dengan resitasi menjawab pertanyaan. Dimana nilai eksperimen 1
63,62 dan nilai kelas eksperimen 2 adalah 60,67 .

Kelas eksperimen I memiliki nilai rata-rata yang lebih tinggi dari pada kelas eksperimen II. Hal ini karena kelas eksperimen I diberikan resitasi peta konsep. Resitasi peta konsep ini lebih menuntut mahasiswa untuk banyak membaca sehingga mereka bisa menemukan konsep sendiri. Menurut Helmiati (2004: 23) ${ }^{[2]}$ "peta konsep dapat membuat proses belajar lebih terarah dan berjenjang sehingga dalam pelaksanaan proses belajar dapat meningkatkan daya serap pelajar terhadap materi yang diajarkan." Jadi, dengan menemukan konsep sendiri pemahaman mahasiswa lebih lama tersimpan dalam ingatan mereka, sehingga proses praktikum berjalan lancar dan berdampak pada ranah afektivitas mahasiswa yang salah satunya mahasiswa mampu menjawab apa yang ditanyakan oleh pembimbing praktikum.

Sementara itu, pada kelas eksperimen II diberikan resitasi berupa menjawab pertanyaan. Hal ini dimaksudkan agar mahasiswa mempersiapkan diri, dan memiliki bekal awal untuk belajar, sehingga pada saat proses praktikum mahasiswa dapat menjawab pertanyaan yang diberikan pembimbing praktikum. Proses praktikum tidak berlangsung satu arah. Adapun keunggulan dari resitasi menjawab pertanyaan ini adalah, mahasiswa lebih terstruktur dalam memahami materi. Pertanyaan yang diberikan pada resitasi ini, pertanyaan yang mengacu kepada cara mahasiswa untuk menganalisis pengambilan suatu informasi dari fakta yang ditanyakan.

Berdasarkan hasil penilaian pada ranah afektif terlihat adanya peningkatan aktivitas belajar mahasiswa dari minggu pertama sampai minggu ketiga, 
peningkatan aktivitas belajar mahasiswa setiap minggunya dapat dilihat pada Gambar berikut ini.

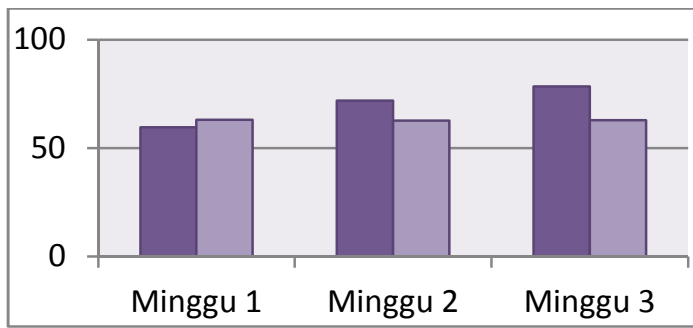

Gambar 1. Grafik Peningkatan Aktivitas Belajar Mahasiswa.

Data pada Gambar 2 untuk kelas eksperimen 1 terlihat peningkatan kompetensi belajar fisika mahasiswa ranah afektif tiap minggunya. Pemberian resitasi, mahasiswa sangat termotivasi untuk belajar. Ketika proses praktikum, tidak ada terjadi praktikum yang satu arah, disini mahasiswa juga berpartisipasi dalam praktikum. Pemberian bekal pengetahuan awal, membuat mahasiswa lebih banyak menanggapi serta melibatkan diri dalam praktikum.

Nasution (2010: 6) mengemukakan beberapa faktor yang mempengaruhi penguasaan seorang pelajar dalam suatu pelajaran yaitu bakat untuk memperoleh sesuatu, mutu pengajaran, kesanggupan untuk memahami pengajaran, ketekunan, dan waktu yang tersedia untuk belajar.

Pada kelas eksperimen II terlihat penurunan nilai afektif pada minggu kedua namun pada minggu ketiga terjadi peningkatan, akan tetapi peningkatan tersebut tidak melebihi pada minggu pertama. Hal tersebut terjadi akibat mahasiswa kurang optimal dalam mengerjakan resitasi menjawab pertanyaan. Mahasiswa tidak dapat menjawab pertanyaan yang diberikan pembimbing praktikum dengan sempurna. Selain itu penempatan jam pelajaran fisika pada jam akhir merupakan salah satu penyebab nilai afektif mahasiswa kelas eksperimen II lebih rendah. Saat praktikum mahasiswa kurang serius mengikuti praktikum, dan kurang memperhatikan dan serius selama pelaksanaan praktikum berlangsung.

Kompetensi belajar mahasiswa pada ranah psikomotor yang diamati adalah keterampilan membuat produk yang dihasilkan oleh mahasiswa berupa peta konsep praktikum dengan resitasi menjawab pertanyaan. Pemberian kedua resitasi tersebut secara keseluruhan, telah mampu dilaksanakan oleh mahasiswa dengan baik. Hasil ini dapat dilihat dari nilai yang diperoleh mahasiswa pada eksperimen 1 dengan rata-rata nilai 63,62 dan eksperimen 2 dengan nilai rata-rata 60,67. Berdasarkan uji hipotesis tidak terdapat perbedaan kompetensi belajar fisika pada ranah psikomotor.

Menurut Simpson, (1956 dalam Sudijono, 2005: 57-58) ${ }^{[6]}$ hasil belajar ranah psikomotor tampak dalam bentuk keterampilan (skill) dan kemampuan bertindak individu. Hasil pengamatan dari rubrik penilaian yang dilakukan, mahasiswa mampu membuat resitasi dengan baik, meskipun masih terdapat beberapa yang belum sempurna dalam mengerjakankannya.

Resitasi berbeda yang diberikan pada kedua kelas eksperimen, yaitu berupa pembuatan peta konsep maupun menjawab pertanyaan pada ranah psikomotor tidak memberikan perbedaan terhadap kompetensi belajar mahasiswa. Kedua resitasi tersebut merupakan bekal awal bagi mahasiswa untuk memahami materi yang akan dipelajarinya. Selain itu, kedua resitasi tersebut merupakan, resitasi yang sama-sama dibuat berdasarkan indikatorindikator praktikum. 


\section{KESIMPULAN DAN SARAN}

A. Kesimpulan

Berdasarkan hasil penelitian, dapat disimpulkan:

1. Terdapat perbedaan kompetensi mahasiswa yang diberi Resitasi Peta Konsep dengan Menjawab pertanyaan Sebelum Praktikum pada ranah kognitif dan ranah afektif.

2. Tidak terdapat perbedaan kompetensi belajar yang diberi Resitasi Peta Konsep dengan Menjawab pertanyaan Sebelum Praktikum pada ranah psikomotor

B. Saran

Berdasarkan hasil penelitian yang diperoleh, peneliti menyarankan beberapa hal berikut ini.

1. Resitasi menjawab pertanyaan sebaiknya diberikan pertanyaan yang lebih mengarahkan mahasiswa dalam menganalisis serta menyimpulkan dari informasi yang ditanyakan.

2. Diharapkan kepada pembimbing praktikum yang memberikan resitasi, agar mengecek resitasi yang dibuat oleh mahasiswa sebelum proses praktikum dimulai agar menghindari kecurangan dari mahasiswa.

\section{REFERENSI}

Arikunto, Suharsimi. 2008. Dasar-dasar Evaluasi Pendidikan. Jakarta. Bumi Aksara

Helmiyati. M, (2004). Peningkatan Akativitas Belajar Biologi siswa Melalui pemberian Tugas "Concept Map". Jakarta: Jurnal Wawasan Pendidikan Dan belajar.
Lufri. 2007.Kiat Memahami Metodologi dan Melakukan Penelitian. Padang:UNP Press.

Purwanto, M. Ngalim. 2012. Prinsipprinsip Evaluasi Pengajaran. Jakarta : PT. Remaja Rosdakarya.

Slameto. 2001.Belajar dan Faktor yang Mempengaruhinya. Jakarta : Rineka Cipta.

Sudijono, Anas. 2005. Pengantar Evaluasi Pendidikan. Jakarta : PT. Raja Grafindo Persada.

Sudjana. 2005. Metoda Statistika. Bandung : Tarsito.

Suprijono, Agus. 2009. Cooperative Learning.Yogyakarta; Pustaka Pelajar

Trianto. 2007. Mendesain Model belajar Inovatif-Progresif: Konsep, Landasan, dan Implementasinya pada Kurikulum Tingkat Satuan Pendidikan (KTSP). Jakarta: Kencana.

Zanelia. 2011. Pengaruh Pembuatan Peta Konsep oleh Siswa dalam Pembelajaran Kooperatif Tipe Team Assited Individualization Terhadap Hasil Belajar Fisika Kelas VIII SMPN 15 Padang. Skripsi. Padang FMIPA Universitas Negeri Padang. 